\title{
Disturbance Effect on Time-Dependent Yield Stress Measurement of Bentonite Suspensions
}

REFERENCE: Yoon, Jisuk and El Mohtar, Chadi, "Disturbance Effect on Time-Dependent Yield Stress Measurement of Bentonite Suspensions,” Geotechnical Testing Journal, Vol. 36, No. 1, 2013, pp. 1-10, doi:10.1520/GTJ20120082. ISSN 0149-6115.

\begin{abstract}
Disturbance effect on time-dependent yield stress measurement of bentonite suspension was investigated using vane and cone and plate geometry. With cone and plate geometry, the disturbance occurs as a result of the large strains the suspensions are subjected to when placed on the lower plate and when the cone is lowered to the testing position before the actual shear stress is applied. As an alternative, vane geometry has been used to measure yield stress in bentonite suspension to (1) minimize the placing disturbance, and (2) eliminate the loading disturbance. Even though a minimal amount of disturbance was still induced by vane geometry, it was assumed that the amount of disturbance was small enough to be ignored compared to that with cone and plate geometry. Yield stresses of bentonite suspensions at different weight fractions and various resting times were determined from stress ramp tests. Linear relationships were developed between yield stresses measured with the different geometries. Disturbance rapidly increased up to approximately $50 \%$ with resting times, then converged at long resting times (60\% at 10 days). This indicates that cone and plate geometry significantly underestimated the actual yield stress of the tested material because of disturbance. Based on the quantified disturbance, a method to predict the undisturbed yield stress from disturbed one was proposed. The observations were interpreted with structural kinetics.
\end{abstract}

KEYWORDS: yield stress, thixotropy, rheometry, disturbance, bentonite

\section{Nomenclature}

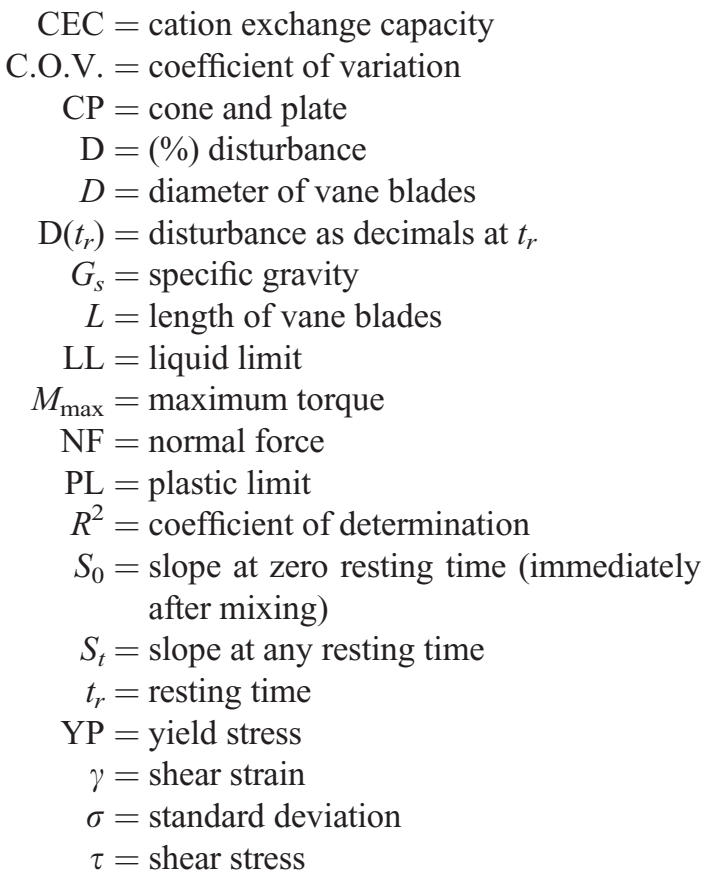

Manuscript received August 31, 2011; accepted for publication August 16, 2012; published online December 10, 2012.

${ }^{1}$ Fugro Consultants, Inc., 6100 Hillcroft Ave., Houston TX, 77081, United States of America.

${ }^{2}$ Dept. of Civil, Architectural and Environmental Engineering, The Univ. of Texas at Austin, Austin, TX 78712-0280, United States of America (Corresponding author), e-mail: elmohtar@mail.utexas.edu

$$
\begin{aligned}
\tau_{y, \text { disturbed }}= & \text { measured yield stress from cone and } \\
& \text { plate at } t_{r} \\
\tau_{y, \text { undisturbed }}= & \text { predicted yield stress from vane at } t_{r} \\
\left(\tau_{y, \text { vane }} / \tau_{y, \text { cone }}\right)_{t r=0}= & \text { correlation between yield stresses meas- } \\
& \text { ured from two geometries at } t_{r}=0 \\
\tau_{y}= & \text { yield stress }
\end{aligned}
$$

\section{Introduction}

Bentonite is a common material used in various industrial applications including foods, cosmetics, paints, and civil and petroleum engineering. Specifically, bentonite has been widely used in the form of suspension (slurry walls, grouts, and boring fluids) in civil engineering. In permeation grouting, rheological properties of grouts, such as yield stress and viscosity, are decisive factors to characterize grout flow through granular soils and rock fractures. For such applications, there is a need to determine both, the initial yield stress (for flow control during permeation) and the yield stress at various resting times (for "washing out" or stability control under no-flow conditions).

The initial value of yield stress (immediately after mixing) is of vital importance to estimate the maximum propagation of grouts through sands/rocks because it controls the stoppage of grout flow when the filtration is relatively small (Gustafson and Stille 1996; Axelsson and Gustafson 2007; Axelsson et al. 2009). On the other hand, the yield stress after varying resting times is a useful parameter to evaluate long-term performance of grout (grout washing by hydraulic gradient of ground water or gravity 
settling) after grout is placed in pores or fractures. Previous research (Cambefort 1964; Axelsson 2006; Liu and Neretnieks 2006) showed that the minimum pressure gradient to mobilize grout permeated into granular soils and rock fractures, or erosion resistance of grout, is related to the yield stress of the permeated grout. For such analysis, the use of the "disturbed" yield stress underestimates the long-term stability of grout under external hydraulic pressures in the field, forcing engineers to use higher solid content of grout, and thus, leads to an uneconomical grouting design. Therefore, the "undisturbed" (at no-flow condition) yield stress must be measured for the long-term analysis of the stability of the grouts in the permeated medium.

Parallel plates, cone and plate and bob and cup are some of the common geometries used to investigate the yield stress of grouts, with the cone and plate geometry being the most used geometry (Nguyen et al. 2006). A strain or stress controlled test (constant shear rate or stress ramp, respectively) is performed to determine the yield stress of grouts based on the measured shear-stressshear-strain (or torque-time) relationship (Coussot 2005). This paper evaluates the inherent disturbance imposed on the aged grout specimens when using the standard cone and plate geometry to measure the yield stress.

\section{Background}

There is no consensus as to the existence and definition of the yield stress (Cheng 1986; Barnes 1999; Barnes and Nguyen 2001; Uhlherr et al. 2005); however, the yield stress is practically defined as shear stress where a fluid starts to flow (Barnes 1999). However, its measurement is challenging because it highly depends on the measuring systems used, the testing programs, and the interpretation methods (Nguyen et al. 2006). It is especially challenging to obtain an "undisturbed" structural state in fluids prior to time-dependent measurements because they are susceptible to disturbance during the setup for testing when using the conventional geometries (cone and plate, plate and plate, and bob and cup).

To eliminate the disturbance and provide consistent initial conditions, preshearing is typically applied prior to yield stress measurement (Ketz et al. 1988; Coussot et al. 2002, 2006; Bekkour et al. 2005; Uhlherr et al. 2005; Mahaut et al. 2008). The preshearing technique provides consistency in the initial yield stress measurements under flow conditions; this measurement is desirable for the initial grout yield stress (immediately after mixing) because the grouts will be flowing during the grouting process. However, for the post-grouting analysis where the grout is not mobile inside the soil/rock, the measurement of yield stress after a long resting period becomes difficult. The samples should remain in the rheometer for the entire resting time (a few days to months) after preshearing to achieve long-term measurements with minimal disturbance. More importantly, it will be practically impossible to prevent evaporation of water from the small amount of sample in such a long time. The more practical approach would be to store suspensions in the separate vessels (or one large vessel) under well-controlled environments (humidity and temperature), and then scoop a certain amount of suspensions on the plate or cup with a minimal disturbance (careful sampling). Despite careful treatment of the sample, the placement of the measuring system (the cone) disturbs the sample, leading to an underestimation of the yield stress. The squeeze flow approach can be used with normal force measurements, but it produces transient and inhomogeneous flow with difficulty in ensuring correct boundary conditions (Engmann et al. 2005). In addition, disturbance during loading samples (scooping) may affect normal stress measurements, especially when the yield stress of fluids is relatively small.

Alternatively, a vane geometry can be utilized for the measurement of the "undisturbed" yield stress. This geometry has been widely used for measuring yield stress of thixotropic fluids such as bentonite suspensions (Benna et al. 1999; Coussot et al. 2002, 2006; Mahaut et al. 2008), food systems, bioengineering systems, and various types of dispersions (Barnes and Nguyen 2001) over the past 30 years. In vane geometry, the thin blades of the vane geometry minimize disturbance (Cheng 1986; Barnes and Carnali 1990; Barnes and Nguyen 2001). By resting samples in separate cups for the desired resting times, disturbance during sample loading can also be avoided. In addition, the measurement is less affected by large particles because a narrow gap is not present. Because yield behavior occurs only within the sample, wall slip, which is typically concerned in cone and plate geometry, can be avoided by using the vane geometry (Keentok 1982; Stokes and Telford 2004). However, vane geometry has the same storage problem as that mentioned for cone and plate if the samples need to be aged while in the rheometer. Therefore, separate storage cups are required to test the samples at different resting times without having disturbance induced by sample placement into cup.

Despite of some disadvantages, cone and plate are still preferred over vane, particularly: cone and plate geometry (1) requires small sample size, (2) produces homogeneous flow, and (3) does not require many storage cups for a specific project. Therefore, one may prefer to use cone and plate for measuring yield stress after a long resting time even though there is obvious disturbance effect on the measurement. In this case, a quantification of disturbance is crucial to evaluate "undisturbed" yield stress from "disturbed" yield stress, resulting in more accurate evaluation of the post-grouting performance.

In this study, the degree of disturbance induced by the cone and plate geometry was quantified based on a linear relationship between the yield stresses measured by both geometries (cone and plate, and vane) for different bentonite fractions. Based on the degree of disturbance, an attempt was made to predict "undisturbed" yield stress from "disturbed" yield stress. In addition, the mechanism of disturbance is explained by breakdown and recovery of the network structures in bentonite suspensions.

\section{Experimental Methods}

\section{Materials and Sample Preparation}

Wyoming sodium-bentonite (CETCO, CP-200) was used to prepare suspensions. The clay minerals consist of a 2:1 structure formed with an octahedral layer between two tetrahedral layers. 
The particles are plate-like in shape and usually less than 1 or $2 \mu \mathrm{m}$ in size (Mitchell and Soga 1976; Luckham and Rossi 1999). Because raw bentonite includes impurities, such as plagioclase feldspar, orthoclase, and muscovite minerals (Abend and Lagaly 2000) and large particles $(>75 \mu \mathrm{m})$, the raw bentonite was screened through a No. 200 sieve to minimize the impurities and their effects on the results (Clarke 2008). No further purification and gradation were applied to simulate mass production of the material for field applications. The mineral has the swell index (i.e., ASTM D5890) of $8 \mathrm{ml} / \mathrm{g}$ when it is hydrated, resulting in a change of rheological properties (Besq et al. 2003). The physical properties of the bentonite are summarized in Table 1. Because the rheological properties of bentonite suspensions vary with $\mathrm{Na} / \mathrm{Ca}$ ratio (Lagaly 1989), Philips/FEI XL30 Environmental Scanning Electron Microscope (ESEM) equipped with energy diffraction analysis of $x$ ray (EDX) was used to characterize chemical composition of the bentonite powder. A gaseous secondary electron (GSE) detector was utilized with frame and spot mode of EDX. The chemical components of bentonite are presented in Table 2. The bentonite used in this study has a $\mathrm{Na} / \mathrm{Ca}$ ratio of 1.9 .

The weight fraction of bentonite in suspensions was calculated by the weight ratio of bentonite to the total weight of suspensions. The initial water content of bentonite was taken into account for calculating the concentration of bentonite suspensions. An average $p \mathrm{H}$ of the suspensions measured using JENCO $60 \mathrm{pH}$ meter was 9.3. Bentonite powder was carefully screened with \#200 sieves and mixed for $15 \mathrm{~min}$ with water. De-ionized water was used to control ionic concentration $\left(2 \times 10^{-5} \mathrm{mM}\right)$ and consistency. The mixing process of bentonite suspensions included three steps; each step consisted of 5 min of mixing by a Hamilton Beach 950 spindle mixer. At the interval, bentonite flocs attached to the cup were removed by manual scraping of the sides and base of the mixing cup.

\section{Test Equipment}

A Physica MCR 301 rheometer, which is an air bearing device manufactured by Anton Paar, was used in this study. The vane is six-bladed, with each blade having a 1-mm thickness and a length of $16 \mathrm{~mm}$. The vane radius is $11 \mathrm{~mm}$ and the cup used has an internal diameter of $29 \mathrm{~mm}$, resulting in a $3.5-\mathrm{mm}$ measuring gap. Additional cups were manufactured for this research for long-term testing; the manufactured cups are $80 \mathrm{~mm}$ in length and $29 \mathrm{~mm}$ in internal diameter. Sample volume was maintained at $37 \mathrm{ml}$, which allowed the vane to penetrate approximately twice the length of its blades. The cone and plate has a diameter of $50 \mathrm{~mm}$ and an angle of $1^{\circ}$. No surface treated plate, such as a serrated plate (Nehdi and Rahman 2004), was used. A peltier hood was utilized

TABLE 1-Physical properties of Wyoming bentonite (CP-200).

\begin{tabular}{lccc}
\hline PL & $38 \%$ & CEC $^{\mathrm{a}}$ & $91 \mathrm{meq} / 100 \mathrm{~g}$ \\
$\mathrm{LL}$ & $440 \%$ & Specific area $^{\mathrm{b}}$ & $712 \mathrm{~m}^{2} / \mathrm{g}$ \\
$G_{s}$ & 2.7 & $p \mathrm{H}$ & 9.3 \\
Initial water content & $8.3 \%$ & Swell index & $8 \mathrm{ml} / \mathrm{g}$ \\
\hline
\end{tabular}

${ }^{\mathrm{a}}$ Methylene blue adsorption test.

${ }^{\mathrm{b}}$ Based on procedures recommended by Santamarina et al. (2002).
TABLE 2-Chemical components of Wyoming bentonite (CP-200), wt. \%.

\begin{tabular}{lrcl}
\hline $\mathrm{O}$ & 53.05 & $\mathrm{~K}$ & 0.52 \\
$\mathrm{Na}$ & 2.27 & $\mathrm{Ca}$ & 1.2 \\
$\mathrm{Mg}$ & 1.52 & $\mathrm{Ti}$ & 0.15 \\
$\mathrm{Al}$ & 9.07 & $\mathrm{Cr}$ & 0.11 \\
$\mathrm{Si}$ & 28.77 & $\mathrm{Mn}$ & 0.2 \\
$\mathrm{P}$ & 0.46 & $\mathrm{Fe}$ & 2.31 \\
$\mathrm{~S}$ & 0.43 & $\mathrm{Total}$ & 100 \\
$\mathrm{Cl}$ & 0.09 & $\mathrm{Na} / \mathrm{Ca}$ & 1.9 \\
\hline
\end{tabular}

to prevent evaporation from the sample edges and maintain a constant temperature during testing. The end effect of vane was considered small enough to ignore for practical purposes (Barnes and Carnali 1990). All tests were performed at room temperature $\left(22^{\circ} \mathrm{C}\right)$.

\section{Experimental Procedures}

The constant shear rate technique has been widely used for vane geometry, but yield stresses determined from this method highly depend on the applied shear rate. In this study, stress ramp technique was selected to develop a relationship between cone and plate and vane geometry. However, yield stresses from the constant shear rate were also compared to those from the stress ramp with vane geometry to eliminate any bias from different testing methods. The following sections show a comparison between the two methods and the experimental issues on yield stress measurement by the constant shear and the stress ramp techniques. The comparison supports the utilization of the stress ramp technique in this study.

\section{Storage of Sample and Setup Procedure}

For cone and plate, the bentonite suspensions were stored in a storage vessel for the designated resting times without any shearing. To prevent water from evaporating during storage, a layer of mineral oil was placed on top of the suspensions. At the time of testing, the oil was completely removed using eye dropper. A small amount of sample was then scooped out from the storage vessel and carefully placed on the plate to minimize any other disturbance during the placement. The cone was lowered to the "trimming" position (to a gap of $0.103 \mathrm{~mm}$ ) with a velocity of $8 \mathrm{~mm} / \mathrm{s}$; this process caused a small extrusion of the suspension. The maximum normal force was set as a $50 \mathrm{~N}$. The extruded portion was carefully trimmed with a flat-bladed spatula; during this processes, the cone is locked in place to prevent it from rotating and thus shearing the samples during trimming. Finally, the cone was moved to the "measuring" position (to a gap of $0.093 \mathrm{~mm}$ ) with much slower velocity of $5 \mu \mathrm{m} / \mathrm{s}$.

With vane geometry, separate storage cups were specially manufactured for this study to test the suspensions at different resting times. The cups were designed to fit in the rheometer without the need to scoop out any of the suspension and the only disturbance to the suspensions occurred from inserting the vane. The vane was inserted with the same velocity of $8 \mathrm{~mm} / \mathrm{s}$ as the initial velocity of cone and plate. The placement of vane may also cause 
some disturbance, but the disturbance was considered small enough to ignore compared to the disturbance from cone and plate. For samples rested for extended periods of time, the cups were tightly sealed, after mineral oil was added on top of the bentonite suspensions, to prevent any evaporation from the samples.

\section{Constant Shear Rate Technique}

Constant shear rate technique with vane geometry directly estimates the yield stress as the peak stress in the torque-time response at a constant shear rate. The vane is fully inserted into the sample and a rotation is applied at a constant but sufficiently slow rate; the change in torque is monitored with time. The yield stress is then calculated using the maximum torque $\left(M_{\max }\right)$ and the dimensions of the vane such as diameter $(D)$ and length $(L)$ of the blades. The yield stress is calculated by the following equation:

$$
\tau_{y}=\frac{2}{\pi D^{2}}\left(\frac{L}{D}+\frac{1}{3}\right)^{-1} M_{\max }
$$

However, it is well known that the yield stress determined by this method is highly dependent on the applied shear rates (Dzuy and Boger 1983; Barnes and Nguyen 2001; Zhu et al. 2001). In this study, constant shear rate tests were conducted with $10 \%$ bentonite suspensions at a range of low shear rates $(0.05,0.08,0.1$, and $0.5 \mathrm{~s}^{-1}$ ) to confirm shear rate dependency of the measured yield stress. Suspensions were rested for $24 \mathrm{~h}$ to remove any effect from bentonite hydration. Preshearing of $20 \mathrm{~s}^{-1}$ for $1 \mathrm{~min}$ was applied to provide a consistent initial condition prior to the measurements. Figure 1 shows the results of constant shear rate tests at four different shear rates. The peak stresses were 105, 110, 115, and $135 \mathrm{~Pa}$ at the shear rate of $0.05,0.08,0.1$, and $0.5 \mathrm{~s}^{-1}$, which indicates that the higher shear rates produced higher peak shear stresses. This result is compatible with data published in the literature; for example, Bekkour et al. (2005) conducted constant shear rate tests with $6 \%, 8 \%$, and $10 \%$ bentonite suspensions at the shear rates of $0.03-2 \mathrm{~s}^{-1}$ and reported that the peak stress increases as shear rates increase. Saak et el. (2001) observed similar phenomena in cement pastes.

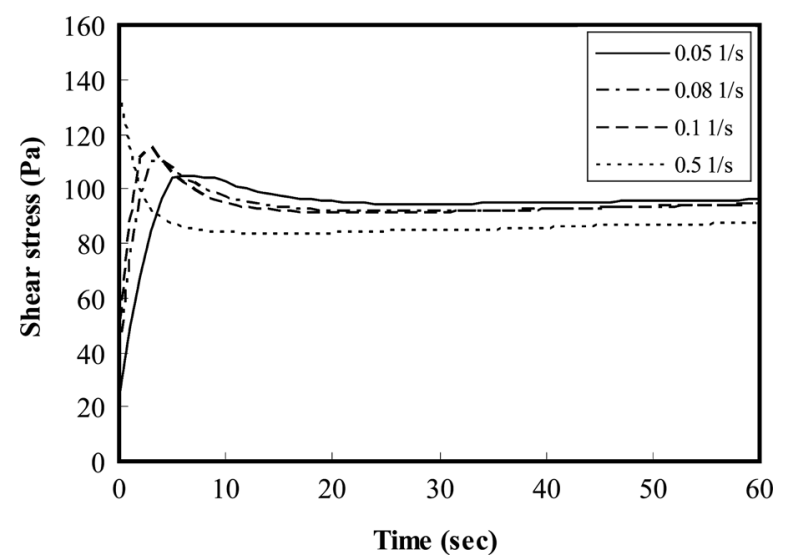

FIG. 1-Shear-stress-time curves using the vane: shear rate dependency in peak stress $(10 \%$ suspensions at constant shear rates of $0.05,0.08,0.1$, and $\left.0.5 s^{-1}\right)$.
Determining a threshold shearing rate, below which the effect of shearing rate becomes minimal, is very challenging because it varies with the bentonite fractions of suspensions. Previous studies (Dzuy and Boger 1983; Barnes and Nguyen 2001) suggested establishing a suitable range of shear rates that produce essentially constant maximum shear stress, and the shear rate should be slow enough to avoid viscous resistance and insufficient damping. In this study, the shear rate may be suitable up to $0.08 \mathrm{~s}^{-1}$ because the difference in peak values was very small $(<5 \%)$. However, the lowest shear rate of $0.05 \mathrm{~s}^{-1}$ was selected to consistently capture yield stress from the diluted to the concentrated suspensions and avoid unforeseen errors in measurements. Nevertheless, peak stress did not appear at $5 \%$ suspensions, indicating that the shear rate of $0.05 \mathrm{~s}^{-1}$ is not sufficiently slow for $5 \%$ suspensions. Barnes and Nguyen (2001) also suggested that this method is the most appropriate for yield stresses greater than $10 \mathrm{~Pa}$.

\section{Stress Ramp Technique}

Stress ramp, a stress-controlled technique, was selected to overcome the shear rate dependency of the measurement in the constant shear rate technique. In this method, the applied shear stress is increased in a stepwise function at a constant rate, resulting in a flow curve. Each stress level is maintained for $12 \mathrm{~s}$ and the rotation is recorded at the end of the interval. The tests were programmed such that samples rested for 2 min after placing the measuring system in the testing position to provide a consistent initial condition for all stress ramp tests (both the cone and plate and the vane tests).

The yield stress is typically determined by fitting models, such as Bingham, Herschel-Bulkley, and Casson, to the flow curve. However, the yield stress obtained from the constitutive models may not have any physical meaning (Zhu et al. 2001), and overestimate the actual yield stress (Coussot 2005). As an alternative, the yield stress can be graphically determined from the shearstress $(\tau)$ - shear-strain $(\gamma)$ curve. Figure 2 shows an example of this method for $10 \%$ bentonite suspension tested using vane geometry. Initially, the shear strain (measured at the end of the $12 \mathrm{~s}$ ) increases linearly with shear stress at a slow rate; this rate increases significantly when the shear stress reaches sufficiently large values and the slope of the stress-strain curve becomes close to zero. For this approach, the plots can be either $\tau-\log \gamma$ or

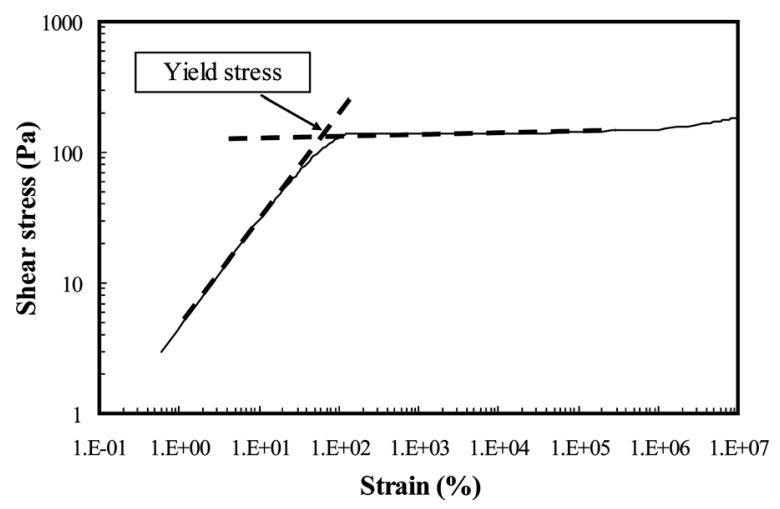

FIG. 2-Example of determining yield stress in stress ramp technique using vane geometry: 10\% bentonite suspension. 


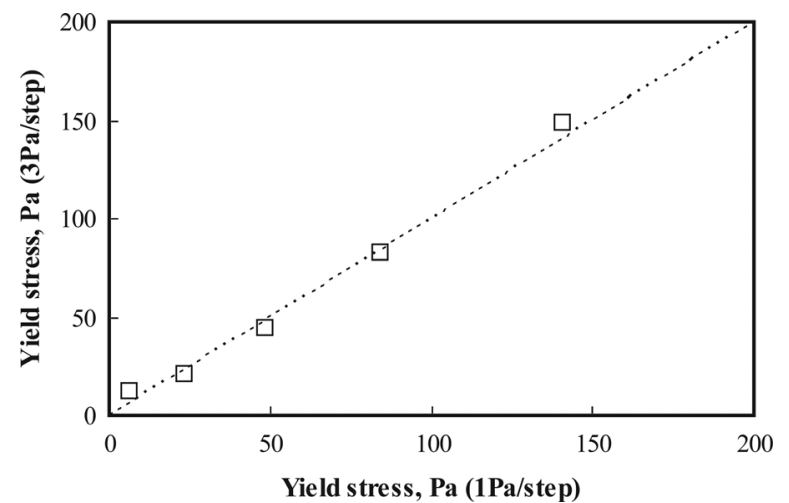

FIG. 3-Comparison of different ramp rates by cone and plate (and Pa/step); each data point corresponds to yield stress in $8 \%, 9 \%, 10 \%, 11 \%$, and $12 \%$ (wt. \%/wt. \%) of bentonite suspensions.

$\log \tau-\log \gamma$ plots. Two straight lines are extended from the solidlike and liquid-like regimes; the shear-stress value at the intersection between these two lines is determined as the yield stress ( $\mathrm{Zhu}$ et al. 2001; Clarke 2008). All yield stress values in this study were determined using the latter method.

The ramp rate is one of the important factors affecting yield stress measurement using the stress ramp technique. Nguyen et al. (2006) observed higher yield stresses at higher ramp rates. However, applying too slow a ramp rate becomes impractical because of evaporation from sample surface (vane) and edge (cone), especially when a fluid has a large yield stress. The evaporation is a larger source of error in the cone and plate measurements because of the small sample size; the vane is inserted deep into the suspension and surface evaporation is less critical on the measured yield stress. Stress ramp tests were performed on $8 \%, 9 \%, 10 \%, 11 \%$, and $12 \%$ bentonite suspensions, immediately after mixing, using cone and plate geometry at two ramp rates: $1 \mathrm{~Pa} /$ step and $3 \mathrm{~Pa} /$ step $\left(0.083\right.$ and $\left.0.25 \mathrm{~Pa} \cdot \mathrm{s}^{-1}\right)$. The specimens were not presheared for these tests because the specimens were tested less than $1 \mathrm{~min}$ after the high shear mixing. As shown in Fig. 3, there was a good agreement between the yield stresses at the two ramp rates, indicating that the differences are small enough to ignore. Based on this result, all stress ramp technique used the ramp rate of $1 \mathrm{~Pa} /$ step for the diluted suspensions (less than $10 \%$ bentonite contents) and $3 \mathrm{~Pa} /$ step for the concentrated suspensions (more than

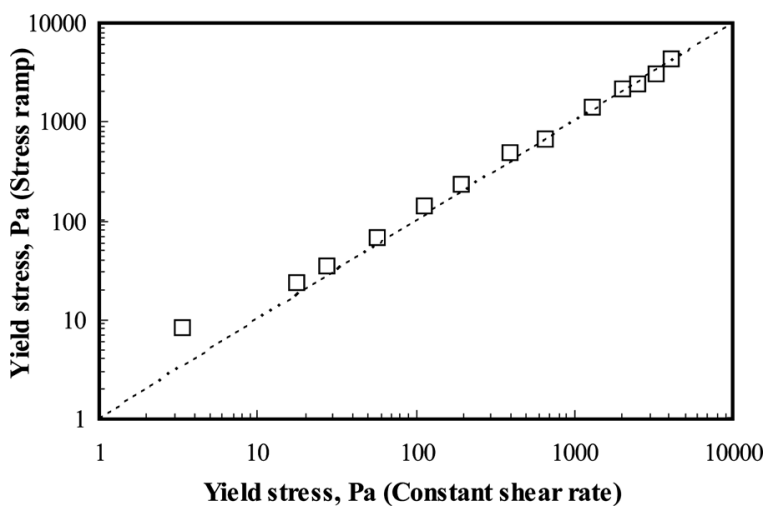

FIG. 4 -Comparison of yield stress from stress ramp and constant shear rate tests with vane geometry (6\%-18\% of bentonite suspensions).

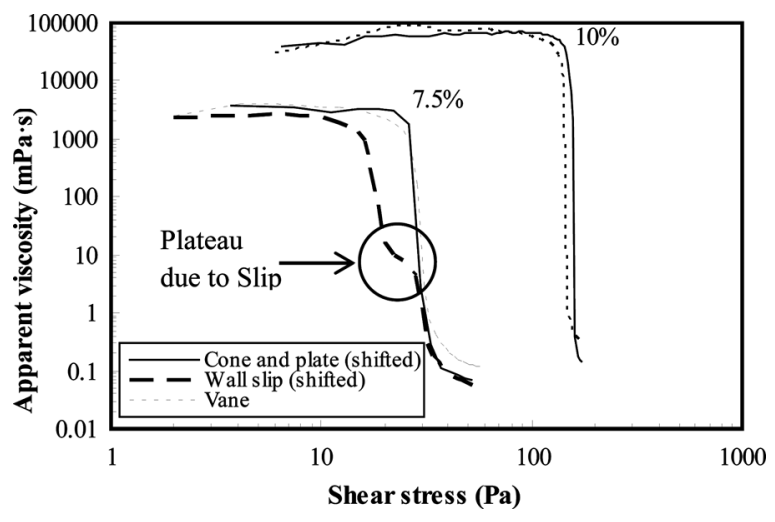

FIG. 5-Wall slip on cone and plate for $7.5 \%$ and 10\% suspensions long dashed line shows occurrence of wall slip).

$10 \%$ bentonite contents) to minimize testing time, and thus, sample evaporation during the tests. The $1 \mathrm{~Pa}$ /step was selected for the more dilute suspensions to increase the accuracy of the measured yield stress.

\section{Comparison of Constant Shear Rate and Stress Ramp Technique}

Peak stresses obtained from constant shear rate tests were compared to yield stresses from stress ramp tests immediately after mixing. Figure 4 displays the yield stresses obtained from the two methods for $6 \%$ to $18 \%$ bentonite suspensions (with $1 \%$ increments). The peak stresses from constant shear rate tests were well agreed with the yield stresses from stress ramp technique, indicating stress ramp technique can accurately estimate the yield stress.

\section{Experimental Results}

\section{Yield Stress at Zero Resting Time}

Figure 5. shows the viscosity-stress curves from cone and plate and vane, for $7.5 \%$ and $10 \%$ bentonite suspensions. Wall slip, which is highly susceptible to occur in the plate-type geometry, was a concern because no treatment was applied. When the

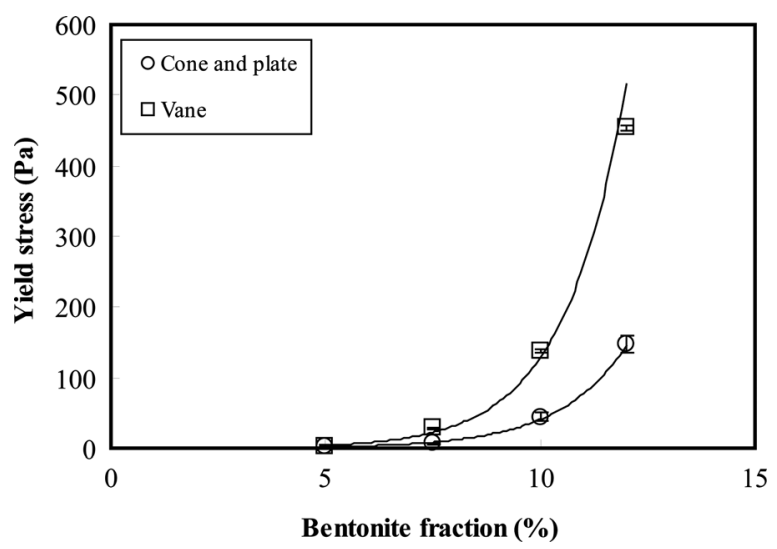

FIG. 6-Yield stresses from cone and plate and vane based on weight fraction of bentonite (wt. \%/wt. \%): $5 \%, 7.5 \%, 10 \%$, and $12 \%$. 


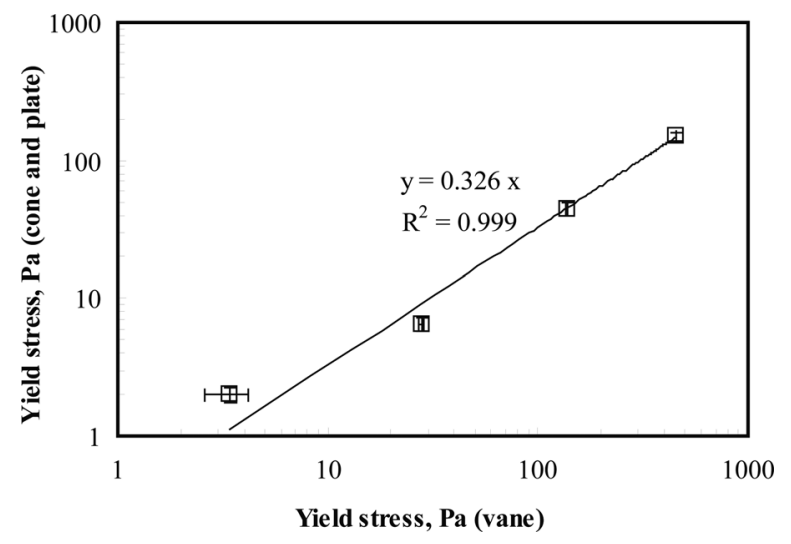

FIG. 7-Correlation between yield stresses from cone and plate and vane at zero resting time.

viscosity-stress curve displays continuous drop without a lowstress Newtonian plateau, it is considered that wall slip did not occur (Buscall et al. 1993). For these series of tests, the stress ramp test was performed immediately after mixing suspensions. Without a rest period, it is assumed that the microstructures of bentonite suspensions reach an equilibrium state during the mixing process, and therefore, there is no effect from disturbance. The hydration of the bentonite particles, which typically takes 16-24 h, may cause some variations for short term measurements (Kelessidis et al. 2007); nevertheless, the suspensions were not hydrated before running yield stress measurements to simulate the state of the suspensions during grouting in the field. The values measured using cone and plate geometry were scaled up (based on the relation presented later in Fig. 7) to match those measured using vane geometry. If viscosity curve from cone and plate showed a continuous trend similar to that obtained from vane, it was considered that no slippage occurred (dashed line). However, if a plateau (or sudden discontinuity) in apparent viscosity was observed (long dashed line), it was considered that wall slip occurred. In the latter case, yield stresses are significantly underestimated. Cone and plate tests that showed slippage were disregarded and excluded from all the results presented in this study.

Figure 6 shows yield stress growth with weight fractions of bentonite (wt./wt. \%) for cone and plate and vane geometry im-

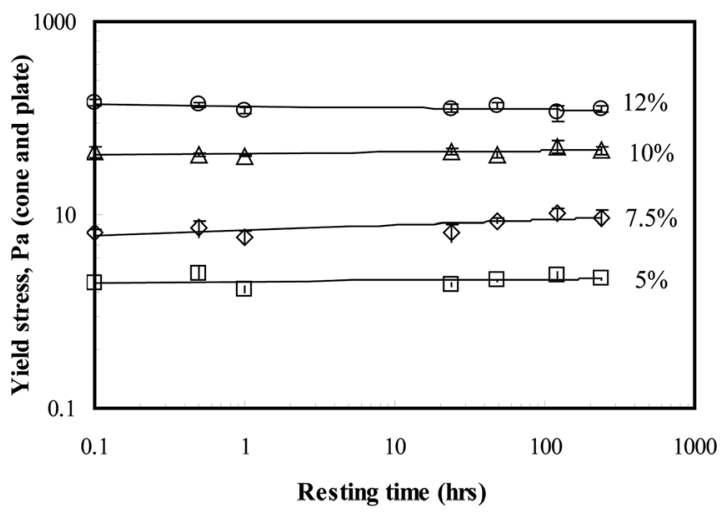

$\mathbf{a}$

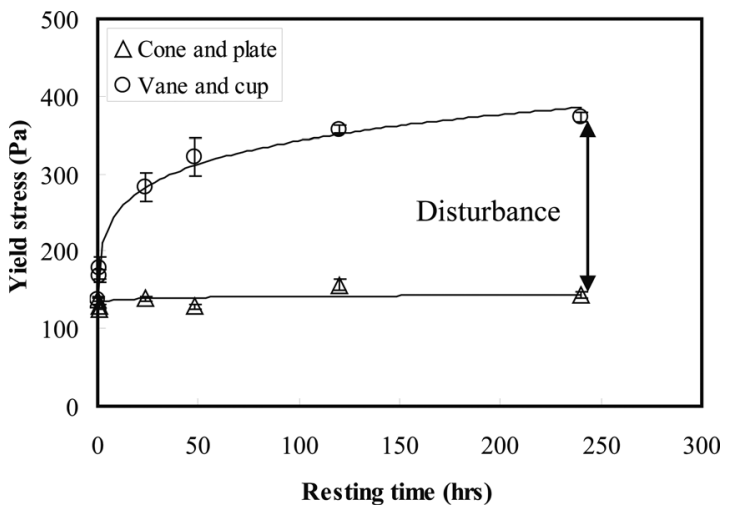

FIG. 9-Comparison of yield stress from cone and plate and vane: $10 \%$ bentonite suspensions (yield stresses from cone and plate were corrected with the factor of 1/0.326).

mediately after mixing. Because all tests were performed immediately after mixing, the difference in yield stresses measured is because of the difference in geometries and not disturbance. The average yield stresses from both geometries increased exponentially with the increase of weight fraction of bentonite, indicating that the yield stress is a function of particle fraction in clay suspensions (Dzuy and Boger 1983). However, vane geometry consistently provided higher yield stress values than cone and plate geometry. At higher weight fraction of bentonite, a larger difference in yield stress was observed; a linear relationship between the yield stresses from the two geometries shown in Fig. 7. The slope and $R^{2}$ were 0.326 and 0.999 , respectively. However, yield stresses at $5 \%$ appeared to be small offset with large standard deviations, indicating that the ramp rate of $1 \mathrm{~Pa} / \mathrm{step}$ does not accurately capture the yield stress for the diluted suspensions.

\section{Yield Stress at Various Resting Times}

Bentonite suspensions are thixotropic fluids that show an increase in yield stress with resting time. Bentonite suspensions with the weight fractions of $5 \%, 7.5 \%, 10 \%$, and $12 \%$ were tested at the resting times of $0.5,1,24,48,120$, and $240 \mathrm{~h}$. Figure $8(a)$ and $8(b)$ show the thixotropic increase in yield stress measured by cone and plate and vane geometry, respectively. The measurement

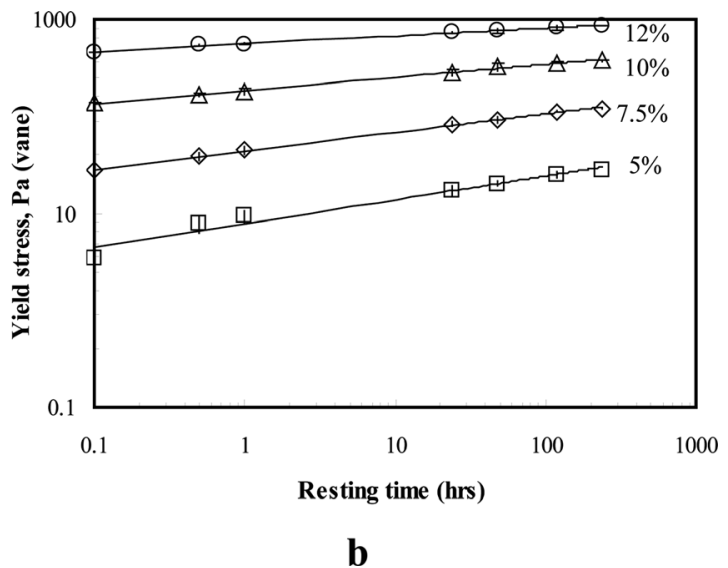

FIG. 8-Yield stress at various weight fractions of bentonite (5\%, 7.5\%,10\%, and $12 \%$ ) and resting times measured by (a) cone and plate, and (b) vane. 
of the yield stress was done without preshearing the sample to capture the disturbance as a result of the testing procedure. Whereas the yield stresses from cone and plate geometry did not show a noticeable increase over time, the yield stresses from vane geometry distinctly increased with resting times. This indicates that cone and plate geometry significantly underestimated the yield stresses as a result of loading the specimen into the rheometer and moving the cone down to the measuring position. Figure 9 displays the comparison of corrected yield stresses from cone and plate with those from vane for a $10 \%$ bentonite suspension. Yield stresses from cone and plate geometry was corrected using the factor of $1 / 0.326$ obtained from the slope at zero resting time. This correction assumes that the ratio between cone and plate and vane remains constant if there are no disturbance effects, which is a reasonable assumption because the ratio was constant over a large range of yield stresses as shown in Fig. 7. As can be seen in Fig. 9, there still exists a large difference between the yield stresses from both geometries, even though the correction was applied. This discrepancy in measured yield stress values is the result of the disturbance occurring during the placement of the specimen on cone and plate and when the cone is lowered to the measuring position, resulting in high strains in the specimen before the stress ramp tests even started.

Figure 10 shows the correlation between the yield stresses from the two geometries at different bentonite fractions and resting times. The correlation between the yield stresses from the two geometries, for the different weight factions of bentonite, was tested in this study for increasing resting times (similar to the correlation presented in Fig. 7 for no resting time). Similar to zero resting time, regression analyses were performed to find a relationship between the two geometries, resulting in linear relationships with $R^{2}$ of 0.980 to 0.999 . The slopes significantly increased at short resting times $(0.5$ and $1 \mathrm{~h})$, and gradually converged at long resting times (120 and $240 \mathrm{~h})$. The magnitudes of the slopes and $R^{2}$ at various resting times are summarized in Table 3 . The magnitude of disturbance was quantified by using the change of the slope with the resting times (a ratio between the reference slope at zero resting time and a slope at a given resting time). The disturbance was assumed to be zero immediately after mixing,
TABLE 3-Regression parameters and disturbance.

\begin{tabular}{lccc}
\hline Time (h) & Slope & $R^{2}$ & Disturbance (\%) \\
\hline 0 & 0.326 & 0.999 & 0 \\
0.5 & 0.256 & 0.999 & 22 \\
1 & 0.217 & 0.998 & 33 \\
24 & 0.171 & 0.993 & 48 \\
48 & 0.167 & 0.980 & 48 \\
120 & 0.139 & 0.996 & 57 \\
240 & 0.135 & 0.992 & 59 \\
\hline
\end{tabular}

Note: Each value presented here is an average value of three samples at each concentration and resting time.

and for other resting times, it was calculated by the following expression:

$$
\mathrm{D}(\%)=\left(1-\frac{S_{t}}{S_{o}}\right) \times 100
$$

where $\mathrm{D}$ is the disturbance (\%), $S_{0}$ is the slope at zero resting time (immediately after mixing), and $S_{t}$ is the slope at any resting time. The disturbance significantly increased at short resting times $(0.5$ and $1 \mathrm{~h}$ ), and gradually converged at long resting times (120 and $240 \mathrm{~h}$ ). With increasing resting times, cone and plate geometry significantly underestimated yield stresses up to approximately $60 \%$. Because this correlation considers a wide range of bentonite fractions, the disturbance becomes only a function of resting time in the proposed application.

\section{Prediction of the "Undisturbed" Yield Stress}

Based on the quantified degree of disturbance, an attempt was made to predict the "undisturbed" yield stress (vane) from the "disturbed" yield stress (cone and plate) by using the following relationship:

$$
\left(\tau_{y_{\text {undisturbed }}}\right)_{t_{r}}=\left(\tau_{y_{\text {disturbed }}}\right)_{t_{r}}\left(\frac{\tau_{y_{\text {vane }}}}{\tau_{y_{\text {cone }}}}\right)_{t_{r}=0} \times \frac{1}{1-\mathrm{D}\left(t_{r}\right)}
$$

Where $t_{r}$ is the resting time, $\tau_{y}$, undisturbed is the predicted yield stress from vane at $t_{r}, \tau_{y \text {, disturbed }}$ is the measured yield stress from

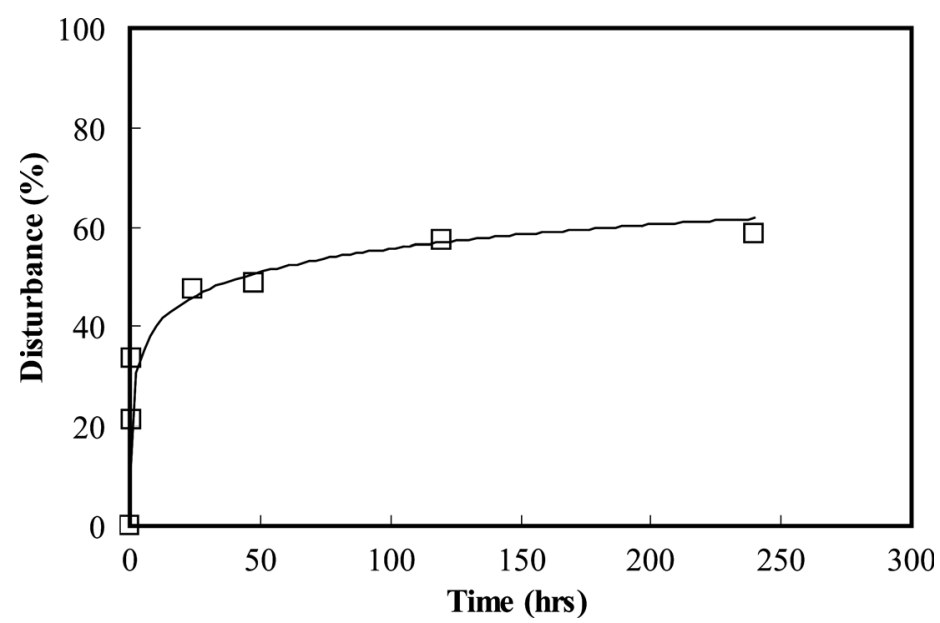

FIG. 10-Average disturbance at various resting times. 
cone and plate at $t_{r},\left(\tau_{y, \text { vane }} / \tau_{y, \text { cone }}\right)_{t r=0}$ is the correlation between two geometries at $t=0$ (in this study, 1/0.326), and $\mathrm{D}\left(t_{r}\right)$ is the disturbance as decimals at $t_{r}$. The proposed correlation considers the yield stress ratio between the two geometries at zero resting time (also after preshearing), disturbed yield stress from cone and plate and the disturbance (which is a function of time).

To validate the proposed model, the undisturbed yield stresses for $8 \%, 9 \%$, and $11 \%$ bentonite suspensions were calculated using yield stresses measured by cone and plate at $0,0.5,1$, and $24 \mathrm{~h}$. The predicted values were compared to the yield stress measured by vane at the same weight factions and resting times. Figure 11 shows the predicted versus the measured values of $8 \%$, $9 \%$, and $11 \%$ bentonite suspensions; the predicted yield stresses agreed well with the measured values. The average ratio of predicted and measured yield stress was 1.0 with the standard deviation of 0.11 and C.O.V of 0.11 . This shows that the undisturbed yield stress can be predicted with a good accuracy using the proposed correlation. This estimation of the undisturbed yield stress is possibly beneficial in that the stability of grouts after any resting times (resistance to the in situ hydraulic gradient) can be estimated from cone and plate results. However, it should be noted that this correlation was developed for the range of 5\%-12\% bentonite suspensions, which are typically used in permeation grouting. Above and below this range, bentonite suspensions are not applicable in permeation grouting because of low efficiency (in case of low bentonite content that does not significantly retard ground water flow or washing) and mixing problem and low penetration depth (in case of high bentonite content).

\section{Discussion}

Structural kinetics of bentonite suspensions may allow us to qualitatively explain the disturbance in yield stress. Depending on $\mathrm{pH}$ conditions, bentonite suspensions have a card-house (Van Olphen 1977) or band-like structure (Norrish 1954; Weiss and Frank 1961) in 3-D space. This structure is continuous and integrated in the suspensions, affecting their mobility: yield stress and viscosity. Nguyen and Boger (1985) postulated that two types of bonds (inter-aggregate and inter-particle bonds) are present in mud suspensions. Inter-aggregate bonds contribute to form a three-

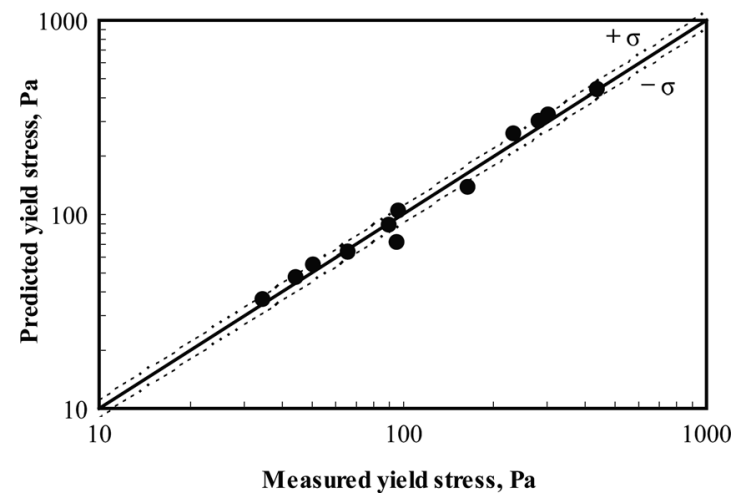

FIG. 11-Comparison of predicted and measured yield stress: $8 \%, 9 \%$, and $11 \%$ bentonite suspensions at $0,0.5,1$, and $24 h$ (the dashed lines are \pm standard deviation lines). dimensional (3-D) network, relating to the strength of the suspensions. These type of bonds can be broken if the applied stress exceeds the yield stress; however, this breakage is reversible with time and the bonds are recovered slowly. Nguyen and Boger (1985) observed that red mud suspensions have a finite yield stress even after long-term mixing, and Jones and Brodkey (1970) observed similar behavior in colloidal alumina suspensions. This indicates that the inter-aggregate-type bonds cannot be completely destroyed even with an excessive external shearing (residual interaggregate bonds).

Inter-particle bonds are dependent on the shear rate. As the shear rate increases, the aggregates are broken into smaller particles, and suspensions become more dispersed. Recovery of this bond occurs practically instantaneously because of inter-particle interaction or bond formation by sudden stoppage of flow (Amorós et al. 2002). Amorós et al. (2002) observed that storage modulus of clay suspensions increased with two different recovery rates: almost instantaneous and slow time-dependent, which correspond to the recovery of inter-particle and inter-aggregate bonds, respectively. The amount of the instantaneous recovery increases with an increase in particle fractions.

The underestimated yield stresses from cone and plate are attributed to the damage of inter-aggregate bonds during scooping, loading the specimen in the rheometer, and positioning the measuring system, and trimming the specimen before running the test. Figure 12 shows the change in normal force at the trimming position (initial compression from lowering the cone on the sample) and yield stresses for $7.5 \%$ and $12 \%$ bentonite suspensions with resting times. The yield stress from vane and the normal force from cone and plate increased with similar rates because of the increase of the amount of network during resting. The rate of recovery or thixotropy is affected by particle movement. In the concentrated suspensions (12\%), Brownian motion of particles is constrained so the thixotropic increase in inter-aggregate bonds is reduced compared to that of the diluted suspensions $(7.5 \%)$. Because of this confinement of particle movement, the rate of increase in normal force is reduced in the concentrated suspensions. However, lowering the cone to the trimming position squeezed the sample and initiated a radial flow (the applied stress by compression is always high enough to induce the flow),

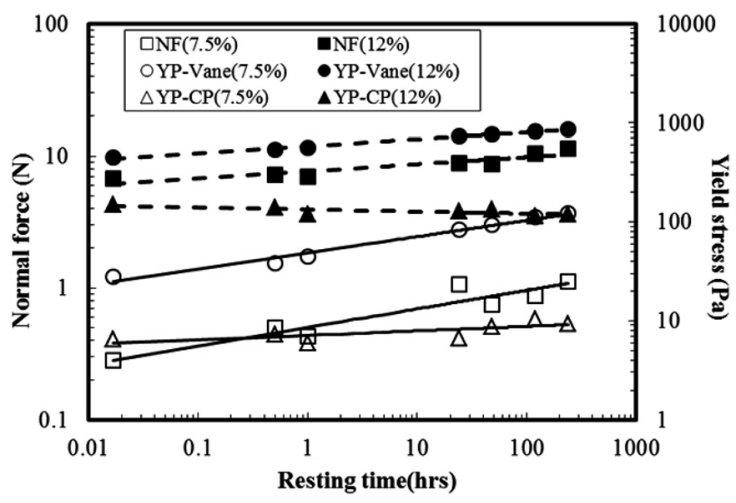

FIG. 12-Normal force and yield stress for $7.5 \%$ and $12 \%$ bentonite suspensions (NF, normal force, YP, yield stress, CP, cone and plate, and the solid and the dashed lines are drawn for the visual aids of $7.5 \%$ and $12 \%$, respectively). 
leading to structural damage in both types of bonds. As the radial flow stops, the inter-particle bonds are recovered rapidly but the inter-aggregate bonds need more time to be recovered, resulting in an underestimation of the yield stress measured by cone and plate at a given resting time. Pignon et al. (1997) observed this change in microstructure of clay suspensions with cone and plate using static light scattering technique; once an applied stress is beyond the yield stress, the microstructure breaks into smaller scales that are different from the at-rest condition.

\section{Conclusions}

Disturbance effect of using the cone and plate on yield stress measurement of aged bentonite suspensions was investigated using cone and plate and vane geometries. Yield stresses measured at increasing resting times using the cone and plate geometry were found to be significantly underestimated because of disturbance. This implies that the thixotropic nature of bentonite suspensions, which is one of important properties required in permeation grouting, could not be accurately measured with cone and plate geometry because of the inherent disturbance imposed during the testing procedures.

The presented work provides a method to measure the aged "undisturbed" yield stress of bentonite suspensions using the vane geometry, which is critical for accurate evaluation of the grout stability inside porous media.

Regression analyses of yield stress measured using the vane and cone and plate geometries, at zero resting time, showed that the yield stress obtained from the vane geometry was lower than that measured using the cone and plate by a factor of 0.326 . Based on this relationship, it was found that using the cone and plate underestimated yield stress of aged bentonite by up to $60 \%$ after long resting times.

Using the quantified degree of disturbance, "undisturbed" yield stress from "disturbed" yield stress could be reasonably predicted. The degree of disturbance was found to be unique for the range of bentonite concentrations studied. Although the proposed model was developed for bentonite suspensions, the same model can be used for different thixotropic suspensions; however, a new disturbance function, $\mathrm{D}\left(t_{r}\right)$ should be developed for the different suspensions. This method is attractive in terms of an optimal usage of equipment and cost-effectiveness.

\section{References}

Abend, S. and Lagaly, G., 2000, "Sol-Gel Transitions of Sodium Montmorillonite Dispersions," Appl. Clay Sci., Vol. 16, pp. 201-227.

Amorós, J. L., Sanz, V., Mestre, S., and Beltrán, V., 2002, "Kinetic Study of Concentrated Clay Suspension Gelling by Dynamic Viscoelasticity Measurements: Effect of Solids and Deflocculant Content," Br. Ceram. Trans., Vol. 101, pp. 194-199.

ASTM D5890-11, 2001, "Standard Test Method for Swell Index of Clay Mineral Component of Geosynthetic Clay Liners,"
Annual Book of ASTM Standards, Vol. 04.13, ASTM International, West Conshohocken, PA.

Axelsson, M., 2006, "Strength Criteria on Grouting Agents for Hard Rock," Ph.D. thesis, Department of Civil and Environmental Engineering, Chalmers University of Technology, Gothenburg, Sweden.

Axelsson, M. and Gustafson, G., 2007, "Grouting With High Water-Cement Ratios-Literature and Laboratory Study," Report No. 2007:5, Department of Civil and Environmental Engineering, Chalmers University of Technology, Gothenburg, Sweden.

Axelsson, M., Gustafson, G., and Fransson, A., 2009, "Stop Mechanism for Cementitious Grouts at Different Water-toCement Ratios," Tunn. Undergr. Sp. Tech., Vol. 24, pp. 390-397.

Barnes, H. A., 1999, "The Yield Stress-A Review or ' $\pi \alpha v \tau \alpha$ $\rho^{\varepsilon} l$ '-Everything Flows?" J. Non-Newtonian Fluid Mech., Vol. 81, pp. 133-178.

Barnes, H. A. and Carnali, J. O., 1990, "The Vane-in-Cup as a Novel Rheometer Geometry for Shear Thinning and Thixotropic Materials," J. Rheol., Vol. 34, pp. 841-861.

Barnes, H. A. and Nguyen, Q. D., 2001, "Rotating Vane Rheometry-A Review," J. Non-Newtonian Fluid Mech., Vol. 98, pp. $1-14$.

Bekkour, K., Leyama, M., Benchabane, A., and Scrivener, O., 2005, "Time-Dependent Rheological Behavior of Bentonite Suspensions: An Experimental Study," J. Rheol., Vol. 49, pp. 1329-1345.

Benna, M., Kbir-Ariguib, N., Magnin, A., and Bergaya, F., 1999, "Effect of $\mathrm{pH}$ on Rheological Properties of Purified Sodium Bentonite Suspensions," J. Colloid Interface Sci., Vol. 218, pp. 442-455.

Besq, A., Malfoy, C., Pantet, A., Monnet, P., and Righi, D., 2003, "Physicochemical Characterization and Flow Properties of Some Bentonite Muds," Appl. Clay Sci., Vol. 23, pp. 275-286.

Buscall, R., McGowan, J. I., and Morton-Jones, A., 1993, “The Rheology of Concentrated Dispersions of Weakly Attracting Colloidal Particles With and without Wall Slip," J. Rheol., Vol. 37, pp. 621-641.

Cambefort, H., 1964, Injection des Sols, Eyrolles, Paris.

Cheng, D. C. H., 1986, "Yield Stress: A Time-Dependent Property and How to Measure It," Rheol. Acta., Vol. 25, pp. $542-554$.

Clarke, J., 2008, "Investigation of Time-Dependent Rheological Behavior of Sodium Pyrophosphate-Bentonite Suspensions," M.S. thesis, School of Civil Engineering, Purdue University, West Lafayette, IN.

Coussot, P., 2005, Rheometry of Pastes, Suspensions and Granular Materials: Applications in Industry and Environment, Wiley, New York.

Coussot, P., Huynh, H. T., Nguyen, Q. D., and Bonn, D., 2002, "Viscosity Bifurcation in Thixotropic, Yielding Fluids," $J$. Rheol., Vol. 46, pp. 573-590.

Coussot, P., Tabuteau, H., Chateau, X., Tocquer, L., and Ovarlez, G., 2006, "Aging and Solid or Liquid Behavior in Pastes," J. Rheol., Vol. 50, pp. 975-995.

Dzuy, N. Q. and Boger, D. V., 1983, "Yield Stress Measurement for Concentrated Suspensions," J. Rheol., Vol. 27, pp. 321-350.

Engmann, J., Servais, C., and Burbidge, A., 2005, "Squeeze Flow Theory and Applications to Rheometry: A Review," J. NonNewtonian Fluid Mech., Vol. 132, pp. 1-27. 
Gustafson, G. and Stille, H., 1996, "Prediction of Groutability from Grout Properties and Hydrogeological Data," Tunn. Undergr. Sp. Tech., Vol. 11, pp. 325-332.

Jones, L. G. and Brodkey, R. S., 1970, "Thixotropic Behavior of a Colloidal Suspension," Proceedings of the 5th International Congress on Rheology, University of Tokyo Press, Tokyo, Japan, Oct 7-11, 1968, Vol. 2, p. 267.

Keentok, M., 1982, "The Measurement of the Yield Stress of Liquids," Rheol. Acta., Vol. 21, pp. 325-332.

Kelessidis, V. C., Tsamantaki, C., and Dalamarinis, P., 2007, "Effect of $\mathrm{pH}$ and Electrolyte on the Rheology of Aqueous Wyoming Bentonite Dispersions," Appl. Clay Sci., Vol. 38, pp. 86-96.

Ketz, R. J., Prud'homme, R. K., and Graessley, W. W., 1988, "Rheology of Concentrated Microgel Solutions," Rheol. Acta., Vol. 27, pp. 531-539.

Lagaly, G., 1989, "Principles of Flow of Kaolin and Bentonite Dispersions," Appl. Clay Sci., Vol. 4, pp. 105-123.

Liu, J. and Neretnieks, I., 2006, "Physical and Chemical Stability of the Bentonite Buffer," Report No. R-06-103, Department of Chemical Engineering and Technology, Royal Institute of Technology, Stockholm, Sweden.

Luckham, P. F. and Rossi, S., 1999, "The Colloidal and Rheological Properties of Bentonite Suspensions," Adv. Colloid Interface Sci., Vol. 82, pp. 43-92.

Mahaut, F., Chateau, X., Coussot, P., and Ovarlez, G., 2008, "Yield Stress and Elastic Modulus of Suspensions of Noncolloidal Particles in Yield Stress Fluids," J. Rheol., Vol. 52, pp. 287-313.

Mitchell, J. and Soga, K., 1976, Fundamentals of Soil Behavior, Wiley, New York.

Nehdi, M. and Rahman, M. A., 2004, "Estimating Rheological Properties of Cement Pastes Using Various Rheological Models for Different Test Geometry, Gap and Surface Friction," Cement Concrete Res., Vol. 34, pp. 1993-2007.
Nguyen, Q. D. and Boger, D. V., 1985, "Thixotropic Behaviour of Concentrated Bauxite Residue Suspensions," Rheol. Acta, Vol. 24, pp. 427-437.

Nguyen, Q. D., Akroyd, T., De Kee, D. C., and Zhu, L. X., 2006, "Yield Stress Measurements in Suspensions: An InterLaboratory Study," Korea-Aust. Rheol. J., Vol. 18, pp. 15-24.

Norrish, K., 1954, "The Swelling of Montmorillonite," Discuss Faraday Soc., Vol. 18, pp. 120-134.

Pignon, F., Magnin, A., Piau, J. M., Cabane, B., Lindner, P., and Diat, O., 1997, "Yield Stress Thixotropic Clay Suspension: Investigations of Structure by Light, Neutron, and X-Ray Scattering," Phys. Rev. E., Vol. 56, pp. 3281-3289.

Santamarina, J., Klein, K. A., Wang, Y. H., and Prencke, E., 2002, "Specific Surface: Determination and Relevance," Can. Geotech. J., Vol. 39, pp. 233-241.

Saak, A. W., Jennings, H. M., and Shah, S. P., 2001, "New Methodology for Designing Self-Compacting Concrete," $A C I$ Mater. J., Vol. 98, pp. 429-439.

Stokes, J. R. and Telford, J. H., 2004, "Measuring the Yield Behaviour of Structured Fluids," J. Non-Newtonian Fluid Mech., Vol. 124, pp. 137-146.

Uhlherr, P. H. T., Guo, J., Tiu, C., Zhang, X. M., Zhou, J. Z. Q., and Fang, T. N., 2005, "The Shear-Induced Solid Liquid Transition in Yield Stress Materials With Chemically Different Structures," J. Non-Newtonian Fluid Mech., Vol. 125, pp. 101-119.

Van Olphen, H., 1977, An Introduction to Clay Colloid Chemistry, Wiley, New York.

Weiss, A. and Frank, R., 1961, "Über den bau der gerüste in thixotropen gelen," Z. Naturforsch, Vol. 16, pp. 141-142.

Zhu, L., Sun, N., Papadopoulos, K., and De Kee, D., 2001, “A Slotted Plate Device for Measuring Static Yield Stress," J. Rheol., Vol. 45, pp. 1105-1123. 